\title{
Can the Discursively Privileged Think?: A Re-Articulation of Social Justice
}

\author{
Alex Christison
}

In this paper I will be interrogating Gayatri Chakravorty Spivak's Can the Subaltern Speak? and Wendy Brown's Wounded Attachments, applying their critiques of the subject to explore a possible re-articulation of the social justice framework. Brown problematizes identities rooted in injury, while Spivak problematizes exterior and interior representation by intellectuals of subaltern voices. Both theorists denounce 'good intentions' as a beneficial factor in emancipation, which leaves contemporary social justice articulations at a standstill. Social justice is premised on egalitarianism, which is both endorsed and contradicted within modern liberal democratic discourse (Brown, 1993, p. 400). Adding to this tension, identities rooted in injury must become invested in their own impotence to express and contest their subjectification (p. 403), while those with access to hegemonic power, such as intellectuals, cannot speak for those lacking access without reproducing and making transparent the very relations and ideals that originally silenced and excluded them (Spivak, 1988, p. 292).

Combining the alternative suggestions given by Spivak and Brown, I argue for a rearticulation of social justice that focuses on the deconstruction and destabilization of all aspects of any discursively privileged consciousness, be it white, male, middle-class, or heterosexual consciousness. This movement is grounded in a political model based on fluid desire, rather than fixed interest, to become Nietzsche's 'angry spectator' who can be a 'redeemer of history,' while reemphasizing translation as both a powerful tool and an imperfect process. I will begin by outlining Spivak and Brown's critiques of the subject, followed by a re-articulation of social justice that avoids the deficiencies illuminated by these authors. This discussion will be highlighted by a self-reflective and deconstructive view of my own consciousness as a middle-class white male within a university institution.

Spivak's (1988) Can the Subaltern Speak? is a direct confrontation with Western intellectual thought's assumed capacity as a neutral and objective investigator of the colonial subject, or subaltern, who lacks access to hegemonic power. Spivak interrogates Karl Marx's two translations of representation, which are distinct yet conflated by Gilles Deleuze and Michel Foucault (p. 275). First, vertreten: to represent, 'as standing in' for a subject whose consciousness is dislocated (p. 277), such as in the case of Western intellectuals speaking for subaltern interest. Second, dartelling: to re-present (p. 275), 'constituting' subjects under a collective or amalgamation (Maggio, 2007, p. 422), such as subalterns speaking for all subalterns, and only on subaltern affairs. Either through being spoken for or being 'permitted' to speak, subalterns are dually silenced and marginalized through representation, and thus are excluded from shaping a discourse on their lives and realities (Maggio, 2007, p. 426).

Western intellectuals discuss the subaltern under a colonizing framework that views knowledge as an extractable resource, appropriating knowledge and rearticulating it through their hegemonic vocabulary, while ignoring "the epistemic violence of [an] imperialism" that re-inscribes the 'third world' as other (Spivak, 1988, p. 289). This approach neutralizes the ideologies within these theorists' "intellectual and economic 
history" (p. 272), denouncing the intricate tie between intellectual production and Western economic interests (p. 271), rendering theorists' positions as transparent (p. 275). Transparency serves to normalize the position of the investigator, while constructing the object of investigation as 'Other' defined by difference. In response to this tendency, Spivak champions Derrida's approach to avoiding too great a transparency through always locating oneself explicitly in one's own discourse (p. 293), as a "self-aware philosopher" (Maggio, 2007, p. 424).

From a Derridean framework, Spivak criticizes Foucault and Deleuze for their assumption that the subaltern "can speak and know their conditions" (p. 283), which essentializes the subaltern as having homogeneous subjectivity and interest (p. 284), and forgets that such messages do not become digestible, or audible, until they conform to the language of dominant interests (Maggio, 2007, p. 431). Through this essentializing process subaltern subjectivity is romanticized, valued as a 'pure' oppressive consciousness (Maggio, 2007, p. 425), the solution to oppression, and as superior to that of the intellectual (Spivak, 1988, p. 274) who ironically re-inscribes their marginality. Thus, the subaltern can only speak as a representative for the subaltern, on subaltern matters, and only in the language of the hegemonic power, which paradoxically requires a removal from the subaltern position, and thus silences their valorized speech (Maggio, 2007, p. 425).

Brown (1993) discusses the paradoxes in modern liberal democracy, such as the tension between universal representation and individualism (p. 391), to detail how difference has become depoliticized through normalized classifications into social positions (p. 393). Political membership in liberal democracy and 'universal' interest are only made achievable through abstracting one's life circumstances and the effects of power that have produced them, and identifying with a collective (p. 392). Through this abstraction, liberal discourse neutralizes the potential for articulations of difference and exclusion to be subversive or critical of power relations, resulting in a conflation of political identity and political interest (p. 393). This conflation collapses difference into a homogenous whole, constructed against a fictitious yet paramount universal 'we', producing the potential for social identities to be managed by regulatory regimes of power (p. 393). Out of this political context emerges modern 'identity politics', which serves to reify difference and exclusion into fixed, depoliticized, categories while naturalizing capitalism (p. 394).

'Identity politics' of modern liberal democracy involves the separation of identity into discrete categories (race, sexuality, gender) in order to be politically meaningful. Brown (1993) suggests that this discourse has only become sensible through a normalizing of "bourgeois culture and economic values" through a re-naturalization of capitalism (p. 394). As capitalism has become re-naturalized, identities based in the exclusion and injury caused by capitalism must instead look to marks of difference to explain suffering. The reduction of difference to observable social attributes does a disservice to identity through viewing difference as intrinsic, rather than the effects of power relations (p. 399). Class based resentments are now reformulated as a matter of justice on the differential axes of gender, sexuality, and race, all of which position their claims against the standard of the white male bourgeois, who is granted "social acceptance, legal protection, relative material comfort, and social independence" (p. 394). Without reference to the white masculine middle-class ideal, injured identities lose their political significance, being taken as a lamenting 'I' opposing the universal 'we' (p. 395); identity based in exclusion requires an 
ideal to be excluded from. The symptom of this inexpressible suffering is that of ressentiment, which will have a profound effect on the social justice framework.

Brown (1993) uses Nietzsche's concept of ressentiment, or the "moralizing revenge of the powerless", the weak triumphing as weak, to describe the synthesis that occurs when the paradoxes of modern liberal democracy are broken (p. 400). All liberal subjects are vulnerable to ressentiment due to the assumptions of self-reliance, which dislocates them from their situatedness within power relations (p. 401). Ressentiment produces feelings of rage and righteousness, which seek a source of responsibility for their pain, in order to "externalize what is otherwise unendurable" (p. 401). By externalizing the source of suffering, guilt is produced on the part of the privileged who themselves serve as proof of a system of suffering, while suffering itself is positioned as a social virtue (p. 403). Identification through ressentiment causes one to become morally superior by vilifying the power relations causing one's subjectification, which ironically involves an involvement with one's own impotence and injury even while trying to escape them (p. 403). In this way, injured identities' history of pain becomes unredeemable, as their suffering is codified cyclically through basing all politically sensible claims in exclusion and injury (p. 406).

If we take both Spivak and Brown's criticisms seriously, we are left with few avenues to which social justice as it is articulated today can be expressed sensibly and that does not re-inscribe subordination as it is being contested. Combining the suggestions presented by each author, I argue for a social justice movement premised on the purposeful and dedicated deconstruction of discursively privileged consciousness.

Since the subaltern cannot shape a discourse of their lives and realities due to the marginalizing effects of representation (Maggio, 2007, p. 426), I reframe the issue around those who can alter the discourse, namely those with a discursively privileged consciousness. While Spivak has justifiably criticized Foucault's practices, his larger methodology is still useful. Drawing on Foucault's discussion of the subject and power from the early 1980's, subjectivity is seen as structured based on the power relations one engages in (1982, p. 781). Power relations are defined by the modes of action made possible (p. 789) as informed by regimes of truth that make discourses function as true, depending on their acquisition and retransmission of certain 'truths' (Foucault, 1980, p. 143). Thus, it is theoretically possible to alter the discourse by altering the subject, who would then fail to respond to such discourses as true, and therefore in effect destabilize them. Such an approach becomes more meaningful as more subjects reject certain discourses and alter their behaviours, potentially beginning a movement. Since "the master's tools will never dismantle the master's house" (Lorde, 2007, p. 112), I suggest tearing down the house from the inside.

Following Spivak's (1988) valorization of Derrida, I argue for a social justice movement that sees the discursive creation of the other as an issue for the discursively privileged consciousness to absolve within ourselves, as an issue for the "benevolent Western intellectual" (p. 292) and the European consciousness (p. 294). That is, it is not for the 'Other' to justify themselves to me, but I who must deconstruct why I have thought them as Other. It is not a matter of "letting the other(s) speak for [themselves]" (p. 294), but rather listening to what my thoughts of the 'Other' reveal about me. Central here is the need for the discursively privileged consciousness to explicitly place itself within its own context (Maggio, 2007, p. 424) to avoid the perils of rendering oneself transparent, and thus normative. This re-formulation avoids the romanticizing of the subaltern consciousness as 
necessary to solve a problem they did not ignite, and rather spurs me to ask myself how I have contributed, and remain complicit, in the subordination of the oppressed and marginalized.

Deconstruction can become politically meaningful through Brown's (1993) concept of the politics of desire, whereby the fixation of identity is avoided by focusing instead on the desire to become, the replacement of 'I am' with 'I want' (p. 407). Just as the injured identity can become unfixed from its injury by reformulating itself as an active desire rather than entrenched in an history of exclusion (p. 407), so too can my discursively privileged consciousness become unbound. I desire to be aware of my own privileges, oppressive actions and thoughts, to produce a destabilizing state of discomfort within myself that does not allow stagnation or ignorance. The politics of desire allows for a productive social justice movement, as identities do not need to reproduce their own injury and exclusion to desire emancipation. Therefore, even though I am seeking emancipation from my own consciousness and not material conditions, I can destabilize myself from a fixed position within a privileged identity to desire something outside of myself. The politics of desire are especially significant in the deconstruction of a discursively privileged consciousness, as a complete deconstruction may never be achievable, though a desire can be everlasting. I may never remove myself completely from the privileged consciousness I possess, but as long as I desire its destabilization, I am capable of more than it has inscribed on me.

One way to imagine the politics of desire in a productive social justice movement is to use Nietzsche's concept of a "redeemer of history" who takes up an "angry spectatorship" of their own history, interrogating its ethicality and morality while viewing it as alterable (Brown, 1993, p. 404). For Nietzsche, it is possible to become self-transformative through critically taking up one's "genealogical consciousness" (p. 404), such as an attempt by a discursively privileged consciousness to examine the history we have benefited from in forms of systematic and institutional privileges. Thus, it is possible to reduce the power of the past and achieve critical politics of desire by "remaking the present against the terms of the past" (p. 404). This task is both a necessity, and a near impossibility (p. 405), yet even in its pursuit, it is more productive than benevolently re-inscribing marginality, or by attempting to forget a history that when ignored carries an even greater weight (p. 405). Injured identities will have difficulty not identifying with their importance until the history that has excluded them has collectively interrogated itself, and thus "reduces the scope of its determinations" (p. 405). Rather than convince the injured identity to 'forget' or move on, as is a common response to contemporary oppression, I argue that those with a discursively privileged consciousness should question their own identification as an abuser, or injurer. Not to be confused with a fixed position at odds with desire based politics, but as viewing abuse as a constant possibility in each power relation the discursively privileged engage in.

As outlined by Brown (1993), re-naturalized capitalist discourses are at the root of many injured identities, rather than the differential axes of race, gender, and sexuality (p. 394). In addition, Laclau and Mouffe (1987) find that capitalism discursively constructs the "subject position of the social agent" (p. 82) by arranging behaviours and identities based on historically and ideologically created capitalist 'interests' (p. 96). Such interests are acquired and internalized due to their necessity in the "participation in collective totalities", which inscribe our capacity to negotiate the forces of capitalism (p. 96). As the holder of a discursively privileged consciousness capable of altering a discourse, and an embodiment 
of the middle-class normative ideal buttressing capitalism (Brown, 1993, p. 395), it is pertinent that I interrogate the history of my interests and their marginalizing capabilities. Laclau and Mouffe (1987), argue that interests "do not exist independently of the consciousness of the agents" who hold them and are susceptible to "dissolution and redefinition" (p. 96). Thus, I recommend that a discursively privileged consciousness become self-interrogating, as a 'redeemer of History", making possible the reconstruction of history through the gaze of the present, and lessening the weight of my ideologically created interests (p. 99). Only through the interrogation of the historical conditions that have lead to the dissolution of identities (p. 104) can emancipatory efforts be granted "a new depth and a new impulse" (p. 105). Through the deconstruction of my discursively privileged consciousness I can alter myself as a subject, and thus have potential to alter the larger discourse.

Neither theory nor multicultural liberalism can solve the issues of the oppressed and marginalized (Maggio, 2007, p. 420), as they either produce their own conditions, while reproducing marginalization, or depoliticize and neutralize difference. In a productive social justice movement, an engagement and understanding of translation must be incorporated. Translation avoids the pitfalls of representation, by never claiming to capture the original message, but rather to place the information in an understandable context ( $\mathrm{p}$. 432). Translation requires a dedicated engagement on the part of the listener to seek an understanding of the conditions and processes that brought about the message they seek to grasp (p. 434). Thus, if I desire to deconstruct my own discursively privileged consciousness by listening to the experiences of the marginalized and oppressed, I must also attempt to know the conditions and presuppositions that contextualize their statements, rather than have a messaged tailored to my hegemonic vocabulary. Translation makes visible the discrepancies between modes of understanding traditionally hidden by normative assumptions (p. 436), thus making criticism of Western discourse necessary rather than exempt. Finally, translation as a pragmatic expression of the deconstruction of a discursively privileged consciousness always requires self-awareness of being privileged.

I have argued for a deconstruction and destabilization of all aspects of any discursively privileged consciousness as a means for the emancipation of the oppressed and marginalized. Applying Spivak and Brown's critique of the subject, a re-articulation has been presented that targets the discursively privileged subject as a means to shape the discourse. By adopting Derrida's approach to otherization, executed using the politics of desire, the discursively privileged can become a 'redeemer of history' through an 'angry spectatorship'. As discursively privileged, we must take it upon ourselves to make emancipatory efforts, not by trying to speak for or represent, but through being self-critical agents in a position to alter oppressive discourses. 


\section{References}

Brown, W. (1993). Wounded Attachments. Political Theory, 21(3), pp. 390-410.

Foucault, M. (1982). The Subject and Power. Critical Inquiry, 8 (2), pp 777-795).

Foucault, M., \& Gordon, C. (1980). Power/knowledge: selected interviews and other writings, 1972-1977. New York: Pantheon Books.

Maggio, J. (2007). “Can the Subaltern Be Heard?": Political Theory, Translation, Representation, and Gayatri Chakravorty Spivak. Alternatives, 32, pp. 419-443

Laclau, E. \& Mouffe, C. (1987). "Post-Marxism without apologies". New Left review, 166 (11-12), pp. 79-106.

Lorde, A. (2007). Sister outsider: essays and speeches. Berkeley, Calif.: Crossing Press. Spivak, G. C. (1988). Can the Subaltern Speak? In Nelson, C. \& Grossberg, L. (Eds.) Marxism and the Interpretation of Culture (pp. 271-313). Urbana: University of Illinois Press 